\title{
NA ENCRUZILHADA DA VIDA: a descoberta do corpo, do sexo e do amor na chegada à adolescência
}

In the crossroads of life: the discovery of the body, the sex and the love in the arrival of adolescence

RESUMO: Neste ensaio, simultaneamente teórico e vivencial, reflito a partir de minha prática profissional em diálogo interdisciplinar com autores do universo da adolescência. Parto do pressuposto de que a vida é feita de encruzilhadas existenciais, sendo que numa delas a adolescência assume lugar de importância. Assumo que na encruzilhada adolescente encontram-se as descobertas que promovem as principais transformações da vida humana. Por isso, darei ênfase a três delas: a descoberta do corpo, do sexo e do amor. Concluo, reconhecendo, que o bom desenlace dessa situação estabelecerá o futuro homem e a futura mulher na vida adulta.

Palavras-Chaves: Adolescência. Corpo. Sexo. Amor.

ABSTRACT: In this essay, theoretical and experiential at the same time, I reflect from my professional practice in interdisciplinary dialogue with authors from the universe of adolescence. I start from the assumption that human life is made of existential crossroads, and in one of them the adolescence takes place of importance. I understand that at the teenage crossroads are the discoveries that promote the most important transformations of life. Thus, I will emphasize three of them: the discovery of the body, sex and love. I conclude, recognizing, that the good outcome of this situation will establish the future man and the future woman in adult life.

Keywords: Adolescence. Body. Sex. Love.

\section{INTRODUÇÃO ${ }^{2}$}

\footnotetext{
${ }^{1}$ No momento encontro-me num doutorado em Psicologia (PPGPsi/UFRN). E-mail: tonlusi@hotmail.com

${ }^{2}$ Esta reflexão foi feita para ser apresentada em grupos de adolescentes, mas acabou ocupando outros espaços, como grupos de professores. Nesta reelaboração procurei manter a fluidez coloquial de sua linguagem, embora possa parecer um texto pouco formal e/ou eivado de cotidianidade.
} 
Nenhuma adolescência pode ser igualada nem na geração que a precedeu nem na que a sucederá. Assim como nenhuma infância, nenhuma velhice, nenhuma adolescência será igual na história da humanidade, porque ela depende de onde e de como está sendo vivida. Aliás, como já mostrou Margareth Mead (1995), a adolescência não é igual no mundo como se fosse um fenômeno vivido de modo universal, dado em todas as culturas. Da maneira como é vista hoje, talvez seja apenas um arranjo situacional da cultura que se desenvolveu no ocidente. A adolescência, por trata-se de uma novidade de ordem geracional permanente, embora fartamente descrita na literatura especializada, ainda não perdeu o seu encanto na contemporaneidade.

Conforme Schoen-Ferreira, Aznar-Farias e Silvares (2010, p. 228): "A palavra adolescência vem do latim adolescere, que significa crescer". Como a ideia de crescimento permeia a vida inteira, o sentido etimológico da adolescência já aponta para um caminho em aberto. Contudo, ninguém é adolescente a vida toda. Mais cedo ou mais tarde a adolescência vai precisar terminar. Logo, tecnicamente falando, a adolescência tem de ter um momento para começar. E aqui já estamos num terreno movediço porque ela tem um tempo para iniciar, e dois ou mais para terminar.

Está marcado que por volta dos 12/13 anos ela se inicia. No Brasil, conforme o ECA - Estatuto da Criança e do Adolescente, o término da adolescência acontece aos 18, quando, por lei, o ser humano recebe o reconhecimento da maioridade (Brasil, 2006).

Aliás, em alguns países, aos 18 anos, os filhos começam a ser 'aconselhados' a deixar a casa dos pais. Na cultura brasileira, apesar de se verbalizar à boca larga que "as famílias devem criar seus filhos para o mundo", a saída dos jovens a partir dos 18 anos não é ainda uma regra geral e inquestionável. Como afirma González Rey (2003, p. 138) "Toda realidade social muda e a incapacidade para acompanhar essas mudanças nas diferentes práticas sociais gera dificuldades de solução muito difícil". Hoje, por exemplo, os estudiosos estão falando de adolescência tardia ou de retardamento para a entrada na idade adulta (Andrade, 2010).

Nas classes médias, muitos jovens estão saindo da casa paterna depois da faculdade, com mestrado e doutorado, e muitos não saem mais. Assim, ao invés dos 18 , hoje se estende aos 30 ou para além disso, dadas as condições sociais, políticas, 
culturais contemporâneas. Desse modo, a adolescência está ganhando uma grande elasticidade.

Caso fosse possível usar apenas o critério biológico, certamente afirmaria que a adolescência deveria ir até a chegada dos 21 anos, que é quando se convencionou o encerramento das possibilidades de crescimento físico, com o fechamento das epífises. Mas, para Araújo, Lunardi, Silveira, Thofehrn e Porto (2011, p. 280): "A adolescência é uma das etapas do desenvolvimento humano que se caracteriza por alterações físicas, mentais e sociais, que recebem interpretações e tratamentos distintos, dependendo do momento e da cultura na qual o sujeito está inserido". Então, onde colocar o término da adolescência? Aos 18 anos, aos 21 ou aos 30, numa adolescência bem tardia? Pois, embora se aceite a alteração física, não se pode negar as demais modificações humanas. $E$ isso cria, do ponto de vista prático, em alguma medida, um problema a ser solucionado. Talvez buscando equacionar esta situação devo dizer que a adolescência constitui-se, como acreditam Santos e Pratta (2012. 171): "[...] como uma vivência liminar e fundamental para a constituição da identidade do sujeito, sendo permeada por mudanças, remodelamentos subjetivos, reinvestimentos pulsionais, retificações e ressignificações de diversas ordens".

Seja como for, talvez fosse mais conveniente falar de final da adolescência, mesmo que aqui se misturasse adolescência e juventude, somente quando o sujeito conseguisse aquela autonomia necessária para viver bem como ser humano adulto independente. Na opinião de Bock (2007, p. 68): "A adolescência se refere, assim, a esse período de latência social constituída a partir da sociedade capitalista gerada por questões de ingresso no mercado de trabalho e extensão do período escolar, da necessidade do preparo técnico". Se o indivíduo vai conseguir isso mais cedo ou mais tarde... paciência.

Pelas dificuldades acima apontadas, parece que falar de adolescência é, antes de tudo, falar sob a égide das metáforas. Para alguns pensadores, a adolescência é um tempo intervalar de preparação que estabelece a passagem rumo à chegada do ser humano na vida adulta (Araújo et al, 2011). Davim, Germano, Menezes e Carlos (2009) chamam-na de fase crítica da vida. Valle e Matos (2010) a denominaram de idade da contradição. Dentro da psicanálise, Maurício Knobel e Arminda Aberastury (1991) concluíram que a adolescência oscila entre o normal e o 
patológico. E a Tânia Zagury (1996) parece intuir que o adolescente só pode ser entendido por ele mesmo.

. Embora eu pense que a vida inteira seja feita desse elemento, para Fierro (1995) a adolescência é a encruzilhada da vida. A encruzilhada é, antes de tudo, uma imagem forte. Ela soa poética, à primeira vista, mas é uma muito carregada de simbolismos. Enquanto metáfora que tenta explicar a adolescência, lembrando, prontamente, escolha, encontro, definição, perda, sofrimento, preparação, coragem, medo, aceitação do real, etc. A adolescência é tudo isso e muitas outras coisas, numa só imagem.

Ao meu ver, nessa encruzilhada ocorrem alterações humanas que contribuem para o fato da adolescência ser uma época de grandes descobertas, sendo algumas delas definidoras da vida. Aliás, as maiores descobertas do ser humano estão se definindo durante a adolescência. Por isso mesmo, é também a época das grandes decisões.

É fácil chegar e sair da adolescência? Não, na cultura contemporânea, para alguns adolescentes, isso é, como popularmente se diz "um verdadeiro angu de caroço", ou "um quebra cabeça bem difícil de ser montado". Tem solução? Tem e seria simples: aceitar a transformação, acolher a descoberta, admitir que se tornou quem se é. Mas, isso leva, geralmente, alguns longos anos da vida humana.

Neste ensaio, simultaneamente teórico e vivencial, reflito a partir de minha prática profissional em diálogo interdisciplinar também com autores do universo da adolescência. Parto do pressuposto de que a vida humana é feita de encruzilhadas existenciais históricas, numa delas a adolescência assume lugar de importância. Entendo que na encruzilhada adolescente encontram-se as descobertas que promovem as principais transformações da vida. Não negando a existência de outras, aqui, darei ênfase apenas a três delas: a descoberta do corpo, do sexo e do amor. Concluo, reconhecendo, que o bom desenlace dessa situação estabelecerá o futuro homem e a futura mulher na vida adulta.

\section{A ADOLESCÊNCIA DESCOBRE O CORPO}

É na adolescência que o ser humano se dá conta de que está mudando. Pra começo vêm as transformações corporais. Heloisa Dantas(1992), falando das 
etapas da construção do eu no pensamento de Wallon, aponta para a importância da explosão da puberdade, chamando-a de canhestria juvenil. Segundo a autora, é nessa etapa, a meu ver também corresponde aos primórdios da adolescência, que se dá a segunda e última crise construtiva. Ela parte de uma ruptura que se dá no nível somático e impõe toda uma reconstrução do esquema corporal. Para ser bem especifico: "(...) é preciso reinstalar-se dentro do próprio corpo e conviver com seus novos apelos" (Dantas, 1992, P. 96).

Ora, ao longo da vida, o corpo sempre esteve e em mutação, os primeiros dentes caíram, nasceram outros novos. As células mudaram diversas vezes. Os cabelos e unhas foram várias vezes aparados. Porém, tudo indica que a pessoa não estava totalmente preocupada com essas questões. Era bem fácil enganar uma criança com a fada do dente, por exemplo. Inquietações com relação ao corpo parecem só começar prá valer quando se chega à adolescência. É como se antes disse, o ser humano não tivesse uma imagem real do seu corpo. Antes da adolescência, se é que se pode dizer isso, quando muito a criança tinha uma vaga noção de sua existência corporal, podendo se ver mais gorda, mais vaidosa, sofrer bulling, etc. Contudo, ninguém conseguirá imaginar o fascínio e as conseqüências trazidas pela descoberta do corpo com a chegada da adolescência. A menina, que vivia de calcinha a correr pela casa, procura se cobrir todinha e fica 'louca' para usar apetrechos de gente grande, tais como sutiã, roupas mais ousadas, maquiagem. Tudo bem que isso já tenha acontecido antes, só que tinha caráter lúdico, invadindo o mundo do faz de contas. Agora não mais. Agora é pra valer. Na adolescência a ludicidade perde o fôlego infantil. É nessa fase que o adolescente começa a levar seu corpo a sério, aliás, a sério demais. Ele se reinstala dentro de si, para, se reparar e ver, como nunca antes e nunca mais para sempre, com todos os ganhos e perdas que isso significa.

Abro aqui um a parte para afirmar isso não estou esquecendo-me de que: "Cada sociedade, cada cultura age sobre o corpo determinando-o, (...) enfatizando determinados atributos em detrimento de outros, cria seus próprios padrões" (Barbosa, Matos \& Costa, 2011, p. 24). De um modo bem próprio, ao que tenho percebido, a cultura contemporânea tem inventado uma enormidade de vitrines para exposição do corpo. Parece que mais do que em qualquer outra época, a nossa quer transformar o corpo num objeto da exposição feliz. E a adolescência não está imune a tudo isso. 
De qualquer modo, fato é que aquele menino, que era magrinho, que os colegas riam dele, chamando-o de "tabica de bater em jumento", de repente começa, como se diz, "a botar corpo", os peitos, que em homem se diz que "não servem para nada" parecem sofrer modificações, em alguns meninos começam a inchar. Surgem pelos em diversos lugares do corpo, os quais vão se diferenciando da face para as partes mais íntimas. Os braços se alongam mais que o normal. Os pés ficam grandes, servindo de mangação, em algumas regiões do país passam a ser chamados de "pés de canoa".

Diferente da menina, parece que o menino vai descobrindo seu corpo por pedaços. E, se não estou enganado, a parte mais valorizada dessa descoberta é a genital. O "pinto", como o pênis e popularmente chamado, que era aquele orgãozinho sem muito significado, por muitos chamado de "varinha de virar tripa", acaba se enchendo, ficando mais roliço e dando uma esticada impressionante, em alguns.

Bem, devo aqui fazer uma pequena digressão explicativa a respeito do órgão genital masculino. Estou defendendo que este é o pedaço do corpo que mais ganha atenção porque isso se intui, especialmente, pela enormidade de apelidos que recebe. Ele é chamado de 'pomba', 'bilau', 'cacete', 'caralho', 'chibanca', 'cambão', 'badalo', 'bimba', 'cabo', 'cipó', 'bilola', 'bilunga', 'torneirinha', 'bronha', 'penisvaldo' e tantos outros epítetos que cada região conhece, alguns os quais já vindo da mais tenra infância.

Nesse encontro do adolescente com seu corpo, além de supervalorizado, o pênis é, talvez por isso, uma das fontes dos maiores sofrimentos masculinos. Em muitos casos, o problema com ele é tão grande que chega ao ponto de fazer o menino tibungar num abismo. Ter um pênis pequeno ou desengonçado demais acaba se tornando uma fonte de azar, chacota e vergonha.

Todo menino, conforme ensinou a tradição psicanalítica, sabia ou se orientava por alguma intuição de que era portador do falo, e o pênis é representante do falo, o que também simboliza o poder do macho. Porém, o reencontro do menino com seu pênis na adolescência vem investido de um poder confuso. É nessa época que o menino mede seu órgão com a régua, somente para ver de que tamanho ele já está. Quem não conhece menino que deixou de usar cuecas, dizendo que era um jeito para seu pênis crescer mais um pouquinho? Alguns relatos dão conta de que há meninos que amarram seu órgão com elástico, no pau da cama e ficam puxando- 
o, dizendo que é para ver se o danado se estica ao máximo e alguns garantem, por puro folclore masculino, que a coisa fica parecendo-se com uma terceira perna.

Quando a escola repara o comportamento de seus alunos, percebe nesse período que os meninos vão ao banheiro em comboios, em alguns casos, apenas para olharem o tamanho do pênis dos colegas. Mesmo jurando que não se incomodam, por vingança risonha, alguns saem dizendo que "tamanho não é documento". Em uma pesquisa realizada no Rio de Janeiro, com 258 jovens, de 17 a 25 anos, de ambos os sexos, sobre questões em torno da dominação masculina, apenas: "[...] oito pesquisadas respondem que o que mais invejam em um homem é o "pênis", enquanto três pesquisados revelam que o que mais invejam em outros homens é o "pênis grande" (Goldenberg, 2005. P. 93). Embora esse número pareça insignificante, como toda roupagem estatística, ele esconde muito, mais também revela bastante, deixando essa pontinha do lado de fora.

No que diz respeito às meninas, a chegada da adolescência também traz enormes mudanças. Muitas, antes tão reprimidas, no reencontro com o corpo nessa fase, parecem se soltar muito. No geral, tornam-se mais ousadas. Na tentativa de valorização de partes do corpo, encurtam a saia, andam se requebrando, dão nó na blusa ou compram sempre a menor que existe na loja. Estão sempre usando de muitos artifícios ou penduricalhos para melhor chamar a atenção. O batom fica mais vermelho, acelerando o valor dos lábios. Até os cabelos têm sempre uma arrumação diferente. E agora com o advento da chapinha, das progressivas, algumas meninas fazem questão de ter cabelos alisados, até as que já os tinham lisos, dando a sensação de estarem sempre prontas para uma festa.

Meninas também sofrem com a chegada da adolescência. Aquelas que têm seios pequenos são muitas vezes massacradas e acabam usando sutiã com enchimento. É bem verdade que muitas, por incômodo com seu próprio corpo, desde muito cedo estão aderindo à prótese de silicone e às plásticas. Mesmo nas camadas populares, aqui se começa a construção de uma mulher ideal, como mostra Aquino (2009). Aliás, esse tem sido um tema sempre quente nas discussões, deixando a tatuagens, que no passado eram um estrondo cultural, uma forma de peitar a família e os costumes sociais mais rígidos, como um tema quase que sem relevância. 
É na adolescência que muitas começam, nessa época, a arrancar as sobrancelhas, fazendo aquela listrinha bem fininha acima dos olhos, dando a sensação de olho inchado ou com sono.

Sendo ou não privilegiada pela genética, aquela meninazinha, que era magrinha, acusada de "tábua de bater bife", na adolescência, percebe que seu corpo muda completamente. Peitos arredondados, bumbum arrebitado, cintura torneada, quadris alargados, começa a formar a futura mulher. Surgem pelos nas partes mais íntimas e nas axilas, os quais devem ser raspados como manda a etiqueta mulher, sob o título de depilação. E aqui se alimenta uma indústria de beleza que muito dinheiro fatura. Mas seria um injustiça dizer isso às moças?

Porém, entre as maiores mudanças femininas da adolescência encontra-se a menstruação, ou a chegada da menarca. Todos os meses elas se confrontam com o incômodo e com o sofrimento das cólicas que somente a natureza poderá explicar e que elas têm de andar prevenidas para não passar por vexame na hora dos desavisos.

Parece que as meninas descobrem o corpo primeiro do que os meninos. Em muitos casos, enquanto a menina já largou a boneca, o menino ainda continua brincando de carrinho por muito mais tempo. Nesse período a necessidade de se mostrar, de dizer "eu existo", parece mais que o normal. Se as meninas pudessem viviam na madame, ajeitando cada ponta de cabelo que se soltasse, retocando a maquilagem, arrancando a sobrancelha, raspando as pernas, fazendo cantinho, depilando as axilas, etc.

É nesse período que os hormônios ligados à sexualidade são produzidos em alta escala. Os professores depois do recreio tendem a reclamar dizendo que "adolescente tem fedor de chifre queimando", ou que "tem catinga de sovaco". Muitos passam a não mais brincar, correr, para evitar chegarem suados à sala de aula. Muitos pais se queixam de que os meninos "gastam frascos de perfumes", não se importando se masculino ou feminino. É uma vaidade impressionante. Os meninos ensebam os cabelos com gel e ficam com aquele topete que parece a cabeça de um desenho animado.

Nas meninas, como nos meninos, na adolescência os hormônios fervem. Os pais sabem disso, porque já foram adolescentes também, e, por isso, começam a apertar as rédeas em todas as situações. Regulam as horas de saídas e de chegada, acentuando-se, frequentemente, o conflito geracional. 
Mas não pensem que descobrir que se tem um corpo é das melhores coisas. A descoberta do corpo indica que o sofrimento está presente. Muitos têm dificuldades de se aceitar. Muito se escondem de vergonha, veem que um monte de espinhas está saindo em seu rosto, etc. Quem nunca ouviu meninas se lamentando com o fato de não poder usar um decote, porque não tinham o que mostrar, pelo fato de ter seios pouco fartos? Quem nunca viu menino vestir calças bem folgadas para esconder pernas finas, aquelas que são chamadas de "pernas de cambitos"?

Quando falo de descoberta do corpo na adolescência estou aludindo não apenas a mudanças corporais. Muda o corpo, está claro. Mas muda também a cabeça, mudam as ideias, as aspirações, os desejos carnais, os sonhos, etc.

Aceitar um corpo em transformação é um trabalho de gigante. Primeiro porque nem sempre o corpo real corresponde ao corpo ideal. É claro que o ser humano é um ser social. Isso significa que ele sofre todos os tipos de influências. Uma dessas influências diz respeito à imagem corporal. Muita gente não fica satisfeita com seu corpo. A insatisfação com o corpo é sempre sinal de insatisfação no campo psicológico. O corpo, que em termos orgânicos deveria ser o lugar do prazer, passa ser lugar de desconforto e dor psicológica. Por isso, tome malhação. Nos últimos tempos alguns meninos malham tanto os ombros, para parecerem maiores, que acabam deixando as nádegas em desproporção. $E$ os colegas que não gostam muito de academia riem deles, chamando-os de 'bundinha chupada'. Recentemente encontrei-me com um rapaz que injetou silicone nos membros superiores e acabou desenvolvendo uma deficiência física em ambos os braços. Muitas meninas também injetam silicone no bumbum e nos seios, mesmo não se livrando a contento daquelas perninhas da grossura de uma agulha, por causa das quais continuam sendo chamadas de Olívia Palito. Os meninos mais gordinhos vivem lotando com "a barriguinha de cerveja", mesmo quando não bebem. Pra que tanto sofrimento? Fico pensando que Marzano-Parisoli (2004, p.19) está correta ao dizer que o corpo "(...) não pode ser aceito a não ser que seja conforme aos modelos cultuais e sociais".

A descoberta do corpo na adolescência é uma coisa bela, mas também e ao mesmo tempo, uma realidade sofrida para alguns.

\section{O PODER DO SEXO NA ADOLESCÊNCIA}


Bem, passo agora a pensar na descoberta do sexo na adolescência. Essa é a segunda maior descoberta desse período. E é claro que todo ser humano sabia da existência de seu sexo antes dessa etapa de sua vida. O menino sabia, por exemplo, que era diferente da menina, que seus órgãos genitais tinham formatos diversos, que ambos receberiam educações diferenciadas etc. $E$ na verdade, mais tarde, em nossas vidas, todos vamos admitir, como observou Ferre (2001, p.207) que "(..) a diferença sexual é a diferença humana fundamental e aquela que possibilita a grande riqueza da diversidade". Afinal de contas, em qualquer lugar, mesmo na família ou na escola, a consideração dada a uma menina não é nunca aquela oferecida a um menino. Portanto, desde muito cedo todos nós vamos percebendo isso. No entanto, a adolescência é a época da descoberta de uma forma plena de sexualidade diferenciada.

Entendo que o sexo e expressão da sexualidade (Foucault, 2003; Chauí, 1991) apesar de precisar de um corpo físico, são realidades sociais e humanas maiores do que a dimensão puramente biológica. A sexualidade humana, como asseguram Jesus, Campos e Alves (2011, p. 97): “(...) não está relacionada apenas ao aspecto corporal, pelo contrário, ela está muito ligada com o ser, com a razão e com os sentimentos de cada um, sendo também uma questão cultural". E ainda como afirma Schindhelm (2011, p. 09): “A sexualidade e seu desenvolvimento são fortemente marcados pela cultura e pela história de cada sociedade, que impõe regras de relevada influência no comportamento dos indivíduos". Sem dúvida, a sexualidade, em suas múltiplas facetas de celebrações dos afetos, está eivada de elementos de discursos históricos, construídos coletivamente, tratando-se pois de uma dimensão importante da existência humana. Por isso, o seu conteúdo culturalmente estruturado não é eterno, nem fixo, nem dado a priori, e muito menos durável para sempre. Mas, de qualquer modo, cabe dizer que descobrir o sexo e a sexualidade é, também, descobrir o corpo. Pois, a descoberta da existência do sexo se dá como possibilidade de contatos corporais prazerosos. Aliás, só os destaquei enquanto possibilidade didática. Porém, é preciso deixar claro que tudo vem ao mesmo tempo.

Embora pareça risível, todo mundo sabe que as conversas adolescentes só têm três assuntos: sexo, sexo, sexo outra vez. A escola apela para não ver. 0 próprio MEC admitiu que a escola não dá à sexualidade a atenção que ela merece 
(Brasil, 2001), o que deveria ser traduzido da seguinte forma: "Ela não sabe o que fazer". Frequentemente esse assunto envolve polêmica na escola. A mais recente foi o chamado Kit Gay, brutalmente incompreendido e cerceado da prática pedagógica nacional pela onda conservadora, quase doente, que assola o país. De qualquer forma, muitos adolescentes trazem revistas pornográficas para a escola, desenham nádegas enormes, que eles chamam de "bundas", rabiscam vaginas triangulosas que eles nomeiam de "bucetas", grafam pênis gigantes nos cadernos, aos quais eles se referem como "rolas". O banheiro escolar nessa época torna-se uma verdadeira revista de interesse singular, que talvez mereça uma consideração muito maior do que a acusação de periódico pornográfico. Suas portas contem verdadeira aula de anatomia humana. Em alguns casos, o banheiro vira o lugar de encontro, de comentários e de exploração da sexualidade.

Definitivamente, nesta época aumenta o número dos palavrões e, para o professorado mais acanhado: "o desembesto é enorme". Mesmo pesado, mas não menos provável, se aplicado à adolescência, sobre o uso dos palavrões na adolescência às vezes assusta. Mas, como afirma Vivian Orsi (2011, p. 335): "[...] a lexia obscena, além de retratar uma cultura, revela a essência do ser humano". Embora esteja presente em outras épocas, na adolescência os palavrões têm uma enorme expressividade. Eles são, inclusive, uma maneira de falar da sexualidade mais abertamente, enfrentando os tabus.

A descoberta do poder do sexo, na adolescência, é também a descoberta do prazer sexual, e isso mexe com o ser humano. Todo corpo, como já disse acima, está sofrendo transformações na adolescência. O que era possibilidade, na infância, torna-se real, plausível, e possível. A antiga criança descobre e toma consciência de que seu sexo pode ser uma fonte de prazer indescritível. Não é mais aquela brincadeirinha inocente de olhar o sexo alheio, de se tocar. Existe agora a probabilidade de um prazer recíproco.

Está claro que a saída da infância para a adolescência promove uma completa revolução na existência. Aquela criança "inocente", que há pouco brincava de boneca ou de carrinho, agora brinca, enquanto não chega o ato sexual, com suas fantasias e com seus genitais em atos masturbatórios, se não tanto reais, ao menos em seu imaginário. 
É na adolescência que muitos meninos e meninas iniciam suas atividades sexuais. Não é ao acaso que os autores se interessam tanto pelo tema da gravidez na adolescência (Gontijo, Carleto, Martins, Alves, 2009).

É bem verdade que muita coisa faz parte da cultura folclórica adolescente. Antigamente, para coibir os adolescentes, alguns adultos diziam que quem se masturbava muito, usando a expressão "bater punheta", nascia cabelos nas palmas das mãos. Quem não caiu nessa armadilha, olhando para as mãos? Quem nunca ouviu dizer de adolescentes de 15 anos que "estavam batendo 08 punhetas por dia". Os pais para meter medo nos filhos adolescentes dizem que "quem se masturba muito acaba ficando amarelo". Já os adolescentes mais danados dizem que "se não descarregarem o óleo, o queijo vai subir pra cabeça". Parece que mesmo em estilo popular, cada cultura, cada comunidade cria estilos para lidar e às vezes controlar a sexualidade do adolescente.

É engraçado que nesse tempo, tanto menino quanto menina parecem sofrer de uma diarreia crônica, que as mães chamam, sem cerimônia, de "caganeira". As mães e pais, que já passaram por essa mesma experiência, começam a dizer às vizinhas: "Ave Maria, esse menino só vive no banheiro".

Outro dia uma menina me perguntou se as adolescentes se masturbavam. Elas fazem as mesmas descobertas dos meninos, salvando-se as devidas diferenças. Ao final de uma outra palestra, uma garota me procurou para dizer que ela própria "socava a caneta lá dentro e ficava achando era bom". Que brinquedinho perigoso. Ela corria o risco de pegar uma infecção. É claro, meninas também se masturbam, embora não digam e nem se gabem, como fazem os meninos. Culturalmente, comportam-se igual, mas agem como se tudo fosse diferente.

Aliás, o prazer veiculado pelo uso das genitálias é um prazer que envolve todo o ser da pessoa. Descobrir o sexo é descobrir, de alguma forma, um mundo do prazer. E, na adolescência, esse prazer é tão completo que vai do dedão do pé até o ultimo fio do cabelo. Está claro, que a parte de maior destaque é a genital, especialmente para o modelo masculino e não tanto para o feminino. Mas as zonas prazerosas não param ai. É aqui que entra, quase que necessariamente, a confusão. Antes, na infância, eram prazeres localizados. Aliás, a psicanálise havia nos ensinado que a sexualidade evoluía por etapas. Primeiro na cavidade bucal, depois na região anal, e por fim na parte genital. Na adolescência, embora a parte genital 
ganhe maior destaque, o prazer passa a se apresentar como fenômeno integrado e pleno.

E aqui está correto dizer como a sexóloga Marta Suplicy (2000) que o poder do sexo se revela tanto na descoberta do prazer quanto na capacidade de procriar. Nisso não somos diferentes dos animais.

Um fato marcante no que diz respeito ao poder do sexo na adolescência é que todas as fantasias infantis voltam com bastante força, revestidas com as cores da loucura e da paixão. É verdade que todas as crianças têm fantasias sexuais, foi a psicanálise quem nos ensinou isso (Klein, 1997). Quando chegam ao período de latência, por volta dos 07 anos de idade em diante, todas as fantasias ficam mais adormecidas. Porém, durante a adolescência elas ressurgem poderosíssimas.

O menino que brincava de papai e a menina que fazia comidinha como se fosse mamãe, no momento do adolescer, descobrem que o mundo do faz de contas acabou-se. Agora é possibilidade real. O menino pode virar, se quiser, papai e a menina pode se tornar mamãe, mesmo que antes da hora. O líquido seminal, que antes não exista, agora é capaz de fecundar um óvulo, gerando um outro ser vivo.

Devo dizer, é nesse estágio da vida que se instala o prazer do risco. Aliás, é na adolescência que muitas pessoas adoram viver perigosamente. A adolescência se esforça para não acreditar nas consequências do perigo. Não adianta: o fogaréu das paixões na adolescência não poupa ninguém, nem mesmo as pessoas mais religiosas. É por conta disso que muita gente, ainda hoje, com todas essas informações de que todos dispõem, acaba cedendo à tentação da carne e engravidando antes da hora. Mas tanto menino quanto menina acreditam piamente que "isso não vai acontecer".

Não dá pra dizer, puritanamente, que sexo não é bom. Claro que é, sexo é ótimo. Mas me parece que deveria ser vivenciado dentro de um enquadre um pouco mais exigente, certamente com mais compromisso e reciprocidade.

Embora aqui eu esteja enfatizando a chegada da adolescência, não posso dizer que todas as crianças desconhecem o sexo. Criança "faz sexo"? As crianças encontradas por Begnami (2010) e de Calaf (2007) disseram que sim. Para ambas, as crianças relataram e admitiram domínio, inclusive, a partir de práticas pessoais de atividades sexuais. Seriam atividades para valer, como fazem os adultos ou teriam diferenças qualitativas significativas? Antigamente, dependendo da cultura local, 
criança "brincava", "pimbava", tinha "enxerimento" ou "fazia safadeza"; Isso era brinquedo e aprendizado.

No passado, quando se chegava à adolescência, se "sarrava" e se "fazia sabão", que era o contato do pênis na entrada na vagina da menina. Isso era o máximo possível, embora não permitido. Mas tudo muda. Hoje os adolescentes, com esse tal de ficar, ficam e já transam sem o menor problema de consciência e, às vezes, expondo-se aos riscos. Acabou-se o mistério. Bauman (2004) estava correto ao indicar que as gerações mais velhas não compreendiam muito bem esse novo modo de se relacionar da cultura juvenil contemporânea. Ao que tudo indica, sexo já não é motivo para se casar.

Perder a virgindade? Bom, isso é coisa do passado. Hoje quando vemos uma personagem de novela reclamar que na idade adulta ainda está virgem, tendemos a rir, pois parece irreal. No passado, como observou Giddens (1993, p. 15) "[...] as mulheres em geral se casavam com sua "virtude" intacta, enquanto que as aventuras dos homens eram consignadas à categoria de uma sexualidade episódica aceitável". Em muitos casos, o pai levava os filhos para um bordel, pagava uma mulher, que ele chamava de "rapariga" e os botava para treinar. Mais tarde, quando eles chegavam ao casamento, já sabiam tudo o que tinham de fazer. Já com a menina era diferente. Ela devia conservar-se casta, imaculada, inocente e intacta até que arranjasse "um dono de casa", "um rapaz de família", só que já bem treinado com as mulheres ditas "putas", para tomar de conta dela. Como me contou certa vez um senhor alagoano, a lei era a seguinte: "O menino deveria, muito cedo, "perder o cabresto", mas a menina deveria guardar bem "o cabaço" até chegar ao altar". No presente, ninguém tem mais paciência de ficar esperando preparações. Cada qual com seu cada qual se prepara como pode, mas já na prática, dizem.

\section{A DESCOBERTA DO AMOR NA ADOLESCÊNCIA}

O coroamento da adolescência ou a manifestação plena da adolescência encontra-se na possibilidade de amar alguém concretamente. Na infância, o menino brincou de amar mamãe, e a menina fantasiou de amar papai, se é que a psicanálise estava correta. Porém, ela viu que isso não era permitido pela cultura, pois as leis de todas as sociedades proíbem o incesto, embora cada uma delas 
tendo seu motivo especial (Levis-Straus, 1992). Então, a paixão pelos pais se desloca para outras pessoas, geralmente, fora dos laços familiares. Na adolescência esse amor, transformado, encontra seu objeto de destino. É o sapo que vira o príncipe encantado aos olhos da menina e é a borralheira que vira Cinderela aos olhos do menino.

Quando um adolescente ama, ama mesmo com todas as forças. Alguns adolescentes se apaixonam facilmente, idealizam rápido e também se decepcionam ligeiro. "Exagerado, jogado aos seus pés, eu sou mesmo exagerado. Adoro um amor inventado". Esse verso de Cazuza define bem o amor adolescente. Todo mundo já viu menino chorar pra morrer, apenas porque a namorada the deu um basta ou foi embora com outro. O amor adolescente é passional no sentido pleno. É capaz de 'matar' ou 'morrer'. O adolescente é capaz de chamar pra viver junto a primeira garota que encontrar e olhe que isso pode acontecer no primeiro fica. Se rolar paixão ele arrisca. O amor adolescente é o único amor sem medo de ser feliz, sem medo de errar. É o único amor não calejado. Claro que a possibilidade de amar, descoberta na adolescência, é uma experiência aberta, mas o adolescente, frequentemente tende a acreditar que só amará uma única vez na vida.

A descoberta do amor tem tudo a ver com a descoberta do sonho romântico. As meninas expressam isso no desejo de casamento, grinalda, véu, igreja, cerimônia tradicional. Elas escrevem cadernos inteiros de poesias e músicas. No menino, isso se expressa no desejo de proximidade.

O amor adolescente quer sempre uma prova. Mas isso é diferente tanto para o menino quanto para a menina. A menina fica feliz com a comemoração de datas, com o fato de receber um cartão, um toque no celular, uma flor, um olhar, uma consideração, uma curtida nas páginas das redes sociais. Já o menino quer uma demonstração de amor, seja manifesta na fidelidade, ou no ato sexual exclusivo.

Antigamente, o adolescente exigia que sua parceira fosse virgem. Entretanto, os costumes mudam. Para González Rey (2003, p. 135): "[...] a representação social da sexualidade muda em cada época histórica concreta, e os elementos subjetivos que participam dessa mudança tem uma gênese muito diversa". Embora não tendo um estudo que elucide essa questão, parece que, atualmente, a exigência de virgindade tende a cair completamente em desuso, se é que ainda sobrou algo dela. A vida sexual tem chegado cada vez mais cedo e isso pode facilitar, inclusive, a liberdade de amar feminina. 
Bem, mas o amor adolescente é um amor que beira o trágico. Quem não conhece história de adolescente dando chilique, bebendo água sanitária, veneno de matar rato, tudo por causa de um amor perdido? Isso na adolescência. Pois somente a adolescência tem a poesia de morrer por amor.

\section{O AMOR HOMOERÓTICO TAMBÉM É ENCONTRADO NA ADOLESCÊNCIA}

Tudo o que disse acima vale para todos os adolescentes, de ambos os sexos e de todas as preferências. Nessa parte, destinarei uma atenção especial àqueles e aqueles que descobriram 0 amor homoerótico na adolescência, apenas por questões didáticas.

Para começo de conversa, parto do princípio de que existem diversas formas de amar. Um poeta contemporâneo chamado Leone disse: "Ainda encontro a fórmula do amor". Essa fórmula não segue necessariamente padrões culturais estritos. Mesmo que em alguns lugares a fórmula tenha de sofrer restrições e constrangimentos, muitos adolescentes amam contra a corrente, como meninos e meninas homossexuais. Eles e elas revelam uma forma de amar que é diferente da maioria ou da hegemonia social. No entanto, merece, enquanto forma de amor, ser respeitada como forma legítima. Pois, como disse Giddens (1993, p. 23): "A emergência da homossexualidade é um processo muito real, com consequências importantes para a vida sexual geral". Portanto, o amor homossexual é legitimo, real e precisa ser considerado não como loucura, safadeza, putaria, doença, depravação, mas como amor entre iguais, tão importante quanto as demais formas de amar mais aceitas pela sociedade.

É importante atentarmos para essa forma de amar, uma vez que ela está tendo um certo destaque na contemporaneidade, tendo inclusive a televisão mais coragem em aborda-la. É bem verdade que não se trata de uma forma nova de amar. Documentos arqueológicos e históricos revelam que o amor homossexual sempre existiu (Taylor, 1997). E registros antigos de proibições estão estampados em algumas partes da Bíblia, o que, acima de qualquer suspeita, só confirma a existência milenar dessa prática. Ora, não faria sentido legislar se não existisse a situação. Diversas culturas, em especial a greco-romana, reconheceram essa forma de amor, embora regulando-a (Foucault, 2003). 
Chamo aqui a atenção para o fato de que escolher é diferente e de preferir. Ninguém escolhe ser homossexual, heterossexual ou bissexual ou o que vier depois. O ser humano se descobre, descobre que essa é sua forma de ser, de amar e de viver no mundo. Ninguém consegue calcular o que é, para um adolescente, ter de enfrentar todos os problemas da descoberta do sexo, da descoberta do corpo e da descoberta de uma forma de amor que ainda é fortemente discriminada pela sociedade e, às vezes, por sua família.

Muitos adolescentes têm medo de assumir essa forma de amar, temem perder seus amigos, serem expulsos da casa de seus pais (Werebe, 1998). Por conta disso, acabam mesmo afundando na depressão, nas drogas, alguns vão para a criminalidade e alguns acabam se entregando ao suicídio ou outras formas de mortes. Negar ao adolescente homossexual o direito de amar é assassinar seu ser.

Descobrir-se adolescente não é fácil, e se torna ainda mais difícil quando o adolescente se descobre preferindo amar contra a corrente.

\section{PALAVRAS PARA FINALIZAR}

É claro que não negando outros elementos importantes, aquilo que chamamos de adolescência está composto pela descoberta desses três elementos interligados: o corpo, o sexo e o amor. Descobre-se o corpo por conta das mudanças estruturais que ocorrem. Assim, a descoberta do corpo é, antes de tudo, uma arrumação da genética, é um reinstalar-se dentro de si próprio. Tudo passa a valer dentro do corpo. Uma vez que o corpo foi descoberto, a adolescente passa a ser em seu corpo. Aliás a sexualidade, como a existência política, cultural e social, precisa de um corpo para se manifestar. Partindo do corpo, o adolescência descobre o sexo e com ele o prazer que dele pode ser extraído. As fantasias nos moldes infantis ficam para trás. Agora é realidade, por vezes beirando o perigo. Por derradeiro, o adolescente encontra-se com amor. Este grande encontro dar-se como possibilidade de elevação de tudo a um plano incomensurável. O amor é a sublimação de tudo, é o coroamento do ser, não importa aqui se visto exageradamente em vermelho.

Bem, é assim que se pode arrumar aquilo que chamamos de adolescência. Esses três elementos trazem consigo, obviamente, transformações na carne e, ao 
mesmo tempo, a transformações da alma humana. Poderia ser fácil se tudo isso fosse aceito sem questionamentos. Mas, em nossa cultura contemporânea nem sempre é.

\section{REFERÊNCIAS}

AQUINO, T. Á. M. Do "se esconder" ao "se mostrar": cirurgia plástica e normalização entre mulheres jovens de classe popular. Dissertação (Mestrado em Psicologia) - Universidade Federal de Pernambuco - UFPE/CFCH. Recife - PE, 2009.

ABERASTURY, A; Knobel, M. A Adolescência Normal. 10ª ed. Porto Alegre: Artes Médicas, 1991.

ANDRADE, C. Transição para a idade adulta: Das condições sociais às implicações psicológicas. Aná. Psicológica. vol.28, n.2, 2010, pp. 255-267.

ARAÚJO, A. C.; Lunardi V. L.; Silveira, R. S.; Thofehrn, M. B.; Porto, A. R. Transição da Adolescência para a Fase Adulta na Ótica de Adolescentes. Rev. enferm. UERJ, Rio de Janeiro, abr/jun; 19(2): 2011, pp. 280-5.

BARBOSA, M. R; Matos, P. M; Costa, M. E. Um olhar sobre o corpo: o corpo ontem e hoje. Psicologia e Sociedade; 23(1): 24-34. 2011.

BAUMAN, Z. Amor líquido: sobre a fragilidade dos laços humanos. Trad. C. A. Medeiros. Rio de Janeiro: Jorge Zahar Ed. 2004.

BEGNAMI, P. S. Crianças: os sujeitos das pesquisas antropológicas. Unar, Araras (SP), v. 4, n. 1, p. 2-12, 2010.

BOCK, A. M. B. A adolescência como construção social: estudo sobre livros destinados a pais e educadores. Revista Semestral da Associação Brasileira de Psicologia Escolar e Educacional (ABRAPEE), Vol. 11, № 1, Jan/Jun, 2007, pp. 63-76.

BRASIL. Estatuto da criança e do adolescente. $3^{a}$. Ed. Brasília: Editora do Ministério da Saúde, 2006.

BRASIL. Parâmetros Curriculares Nacionais - PCN: Pluralidade Cultural: Orientação Sexual/MEC. Secretaria da Educação Fundamental. 3- ed. Brasília, 2001.

CALAF, P. (2007). Criança que faz criança: (des) construindo sexualidade e infância com meninos e meninas de rua. Dissertação (Mestrado em Antropologia Social) -Universidade de Brasília, UNB/PPGAS, Brasília, 2007.

CHAUÍ, M. Repressão sexual: essa nossa (des)conhecida. 12ª ed. São Paulo: Brasiliense, 2001. 
DANTAS, H. A Afetividade e a Construção do Sujeito na Psicogenética de Wallon. In La Taille, Y.; Oliveira, M. K.; Dantas, H. Piaget, Vygotsky, Wallon: teorias psicogenéticas em discussão. 7̣a ed. São Paulo: Summus, 1992.

DAVIM, R. M. B.; Germano, R. M.; Menezes, R. M.V; Carlos, D. J. D. Adolescente/Adolescência: Revisão teórica sobre uma fase crítica da vida. Rev. Rene. Fortaleza, v. 10, n. 2, 2009, p. 131-140, abr./jun.

FERRE, N. P. L. Identidade, diferença e diversidade: Manter viva a pergunta. In Larrosa, J \& Skliar, C. Habitantes de Babel: Políticas e Poéticas da Diferença. Trad. S. G. da Veiga. Belo Horizonte: Autêntica, 2001, p. 195-214.

FIERRO, A. Desenvolvimento da Personalidade na Adolescência. Em Coll, C.; Palácios, J.; Marchesi, A. (Orgs.). Desenvolvimento Psicológico e Educação:

Psicologia Evolutiva. Trad. M.A.J. Domingues. Porto Alegre: Artes Médicas, 1995.

FOUCAULT, M. História da Sexualidade II: $\mathrm{O}$ Uso dos Prazeres. 10 $\underline{\text { a }}$ ed. Trad. M. T. C. Albuquerque. Rio de Janeiro: Graal, 2003.

GIDDENS, A. A Transformação da Intimidade: Sexualidade, amor e Erotismo nas Sociedades Modernas. Trad. M. Lopes. São Paulo: Editora Unesp, 1993.

GONZÁLEZ REY, F. L. Sujeito e Subjetividade: Uma aproximação HistóricoCultural. Trad. R. S. Lobo Guzzo. São Paulo: Pioneira Thomson Learning, 2003.

GONTIJO, D. T.; CARLETO, D. G.S.; MARTINS, S.; ALVES, H. C. Gravidez na Adolescência: Mapeamento da produção científica publicada em periódicos nacionais entre 2003 e 2008. Rev. Triang.: Ens. Pesq. Ext. Uberaba - MG, v.2. n. 2, p. 81-108, jul./dez, 2009.

GOLDENBERG, M. Dominação masculina e saúde: usos do corpo em jovens das camadas médias urbanas. Ciência \& Saúde Coletiva, 10(1):91-96, 2005.

JESUS, J. A; CAMPOS, R. H; ALVES, R. A. A importância da educação sexual e suas contribuições para a formação dos alunos: um estudo nas escolas de educação infantil de Unaí - MG. Revista FACEVV, Vila Velha, № 7, Jul./Dez, 2011.

LEVIS-STRAUSS, C. As Estruturas Elementares do Parentesco. Trad. Mariano Ferreira. Petrópolis: Vozes, 1992.

MARZANO-PARISOLI, M. M. Pensar o Corpo. Trad. De Lúcia M. E. Orth. Petrópolis, RJ: Vozes, 2004.

MEAD, M. Adolescencia y cultura en Samoa. Barcelona/Buenos Aires: Editorial Paidós, 1995.

KLEIN, M. A Psicanálise de Crianças. Vol. II - Obras Completas. Coord. Trad. Liana Pinto Chaves. Rio de Janeiro: Imago, 1997. 
ORSI, V. Tabu e preconceito linguístico. ReVEL, v. 9, n. 17, 2011.

SCHINDHELM, V. G. A sexualidade na Educação Infantil. Revista Aleph Infâncias. Ano V, № 16, Novembro.2011.

SCHOEN-FERREIRA, T. H.; AZNAR-FARIAS, M.; SILVARES, E. F. M. Adolescência através dos Séculos. Psicologia: Teoria e Pesquisa. Abr-Jun, Vol. 26 n. 2, 2010, pp. 227-234.

SUPLICY, M. Conversando sobre Sexo. 21ㅡㅡ ed. Petrópolis: Vozes, 2000.

TAYLOR, T. A Pré-História do Sexo: Quatro Milhões de Anos de Cultura Sexual. Trad. A. Gilson. Rio de Janeiro: Campus, 1997.

VALLE, L. E. L. R.; Mattos, M. J. V. M. Adolescência: as contradições da idade. $2^{\underline{a}}$ ed. Rio de Janeiro: Wak Editora. 2010.

ZAGURY, T. O adolescente por ele mesmo. Rio de Janeiro: Record, 1996.

WEREBE, M. J. G. Sexualidade, Política e Educação. Campinas: Autores Associados, 1998,

SANTOS, M. A.; PRATTA, E. M. M. Adolescência e uso de drogas à luz da psicanálise: sofrimento e êxtase na passagem. Tempo Psicanalítico, Rio de Janeiro, 2012, v. 44.i, p. 167-182. 